\title{
Im Ausland als Arzt erkannt
}

\begin{abstract}
In der MMW-Sonderausgabe 1/2016 berichteten wir auf S. 17 über den langsamen Fortschritt der Planungen für einen Europäischen Arztausweis. Ein Leser verbindet mit dem Projekt Hoffnungen.
\end{abstract}

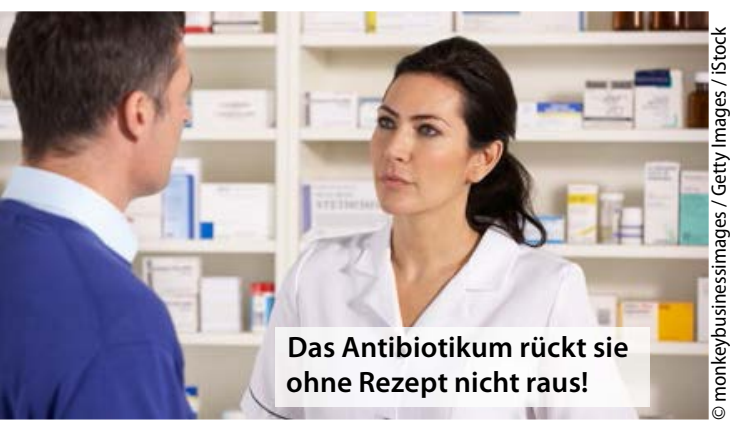

Es ist höchste Zeit, dass ein Europäischer Arztausweis eingeführt wird! Ich frage mich allerdings, welcher Nutzen ein solcher Ausweis für den Arzt mit sich bringt. So hatte ich jüngst, trotz
Vorlage meines gültigen Ausweises, auf Fuerteventura die bittere Erfahrung machen müssen, dass mir ein benötigtes Antibiotikum von der Apotheke nicht ausgehändigt wurde. Ich musste mir zuvor von einem dort ansässigen Arzt ein entsprechendes Privatrezept ausstellen lassen - natürlich gegen ein saftiges Honorar. Auch in Deutschland gibt es ähnliche Schwierigkeiten. Ein gültiger Arztausweis ohne zusätzliches Rezept reicht auch für einen Arzt nicht aus, und das gilt insbesondere im Ausland. Eine Regelung ist nach Auskunft bei der Standesorganisation strittig.

- Dr. Udo Fuchs, Hamburg

\section{Kann die MMW nicht zählen?}

In der MMW-Sonderausgabe 1/2016 stand auf S. 18 eine Anektdote aus der Praxis über ein 1981 geborenes "Mathe-Supertalent", das nicht erkannte, dass es von der Empfehlung für die zweite MMR-Impfung betroffen war. Ein aufmerksamer Leser hat eine Ungereimtheit entdeckt:

Mit Schmunzeln habe ich in dem Artikel gelesen, wie sich ausgerechnet die Autorin über die Genialitäten ihrer Patienten amüsiert. Dabei liegt sie doch selbst einem Irrtum auf! Sie schreibt, dass alle 1970 oder später Geborenen laut STIKO eine zweite MMR-Impfung bekommen sollen. Die Empfehlung gilt aber ihrem Wortlaut gemäß für alle nach 1970 Geborenen - also für alle Patienten mit einem Geburtstag ab dem 1. Januar 1971.

- Dr. Frank Driesner, Ueckermünde (Mecklenburg-Vorpommern)

\section{Rehabilitationsverordnung}

\section{Chance vertan!}

\begin{abstract}
Ebenfalls in der MMW-Sonderausgabe 1/2016 ging es auf S. 16 um die Rehabilitationsverordnung. Die Pflicht, sich dafür fortzubilden, ist seit 1. April 2016 entfallen. Zwei Leser sehen hier eine vertane Chance:
\end{abstract}

_ Da haben unsere Funktionäre wieder „super“ verhandelt! Warum fällt denn die Pflicht zur Fortbildung für die Reha-Verordnung weg? Weil es kaum Ärzte gab, die die Kurse besucht haben. Deshalb konnten die Formulare nicht ausgefüllt werden. Nun waren wir als Ärzteschaft in einer starken Position, und wir hätten extrabudgetär eine vernünftige Honorierung erreichen können.

Das war höchst unprofessionell verhandelt. Das Honorar verdient diese Bezeichnung nicht mehr, und die Kassenärzte sind wieder mal die Deppen der Nation.

- Dr. Katrin Göhring-Frischholz, Dr. Peter Karl Eugen Göhring, Althengstett (Baden-Württemberg)
Fehler im System?

Die Demenzwelle rollt

\author{
In MMW 5/2016 ging es ab S. 10 um die Betreuung \\ von Demenzpatienten. Dazu hat ein Leser eine \\ Anmerkung:
}

„Seit Rechtsanwälte, Psychologen, Pädagogen und Sozialarbeiter von der gesetzlichen Betreuung leben können, hat sich in wenigen Jahren die Zahl der Betreuten auf etwa 1 Million mehr als verdoppelt. Der neue und dynamische Berufsverband will natürlich weiter expandieren und hält daher 6 Millionen Bundesbürger für betreuungsbedürftig." So stand es bereits 2002 im Standesorgan der deutschen Ärzteschaft zu lesen [Dtsch Arztebl 2002;99:A-2462].

Erschwerend kommt hinzu, dass „ältere“ Patienten in ihren Krankenhausentlassungsbriefen häufig die Diagnose Demenz haben. Dabei kommt oft ein passageres Durchgangssyndrom vor, wenn Patienten aus ihrer Narkose aufwachen. Die Diagnose im Entlassungsbrief bahnt aber den weiteren Weg.

- Dr. Hartmut Heinlein, Eschershausen (Niedersachsen) 